\title{
COPA DO MUNDO DE CLUBES DA FIFA (2010-2017): REPRODUÇÃO DA COLONIALIDADE SOB A PERSPECTIVA DO SISTEMA-MUNDO MODERNO
}

\author{
Juliano Oliveira Pizarro ${ }^{1}$ \\ Carmen Silvia de Moraes Rial ${ }^{2}$ \\ Luiz Carlos Rigo 3
}

\begin{abstract}
Resumo
A partir da teoria da Economia Política dos Sistemas Mundo, com um breve diálogo com as teorias pós-coloniais e decoloniais, a pesquisa visa identificar como ocorre a concentração do capital no futebol, analisando as dinâmicas do sistema-mundo e a transformação do jogador em mercadoria, principalmente o fluxo de transferência de jogadores dos países periféricos aos países do centro global, seguindo a lógica colonial. Assim, o estudo pretende contribuir para o entendimento da globalização no futebol, abordando aspectos contemporâneos para entender a espacialização do fenômeno ao redor do mundo, baseado na teoria do sistema-mundo moderno, observando o fluxo de atletas nas Copas do Mundo de Clubes de futebol masculino entre os anos de 2010-2017.
\end{abstract}

Palavras-chave: Futebol; Economia Política Internacional; Colonialidade; Sistema-Mundo Moderno.

\section{FIFA Club World Cup (2010-2017): reproduction of coloniality from the perspective of the Modern World-System}

\begin{abstract}
From the Theory of Political Economy of World Systems, in a brief dialogue with postcolonial and decolonial theories, the research aims to identify how does the concentration of capital in football, analyzing the dynamics of the worldsystem and the transformation of player in merchandise, especially the players transfer of the peripheral countries to the global center countries, following the colonial logic. Thus, the study aims to contribute to the understanding of
\end{abstract}

\footnotetext{
1 Doutorando pelo Programa de Pós-Graduação Interdisciplinar em Ciências Humanas da Universidade Federal de Santa Catarina com período de Doutorado Sanduíche na Universidade de Aveiro (Portugal) no Departamento de Ciências Sociais, Políticas e do Território, mestre em Ciência Política pelo Programa de Pós-Graduação em Ciência Política da Universidade Federal de Pelotas, graduado em Educação Física Licenciatura pelo Centro Universitário Claretiano. E-mail: jopizarro@hotmail.com

2 Professora titular da Universidade Federal de Santa Catarina, pesquisadora do CNPa (Conselho Nacional de Desenvolvimento Científico e Tecnológico), dirige o Núcleo de Antropologia Visual / Grupo de Pesquisa em Antropologia Urbana (NAVI / GAUM). Ela obteve seu doutorado na Universidade de Paris $\vee$ - Sorbonne. Rial é Presidente do Conselho Mundial de Associações Antropológicas (WCAA), co-Presidente da União Antropológica Mundial (WAU) e ex-presidente da Associação Brasileira de Antropologia. Seu trabalho se concentra nos temas de esporte, migração transnacional e gênero e globalização cultural. E-mail: rial@cfh.ufsc.br

${ }_{3}$ Professor titular da Universidade Federal de Pelotas na Escola Superior em Educação Física e no Programa de Pós-Graduação em Educação Física. Possui graduação (Licenciatura) Em Educação Física pela Universidade Federal de Santa Maria (1987), mestrado em Ciências do Movimento Humano pela Universidade Federal de Santa Maria (1993), doutorado em Educação pela Universidade Estadual de Campinas (2001), Pós-doutorado em Educação pela Universidade de Barcelona (2011 2012) e Pós-doutorado no Programa Interdisciplinar em Ciências Humanas (PPGICH) da UFSC (20162017). E-mail: rigoperini@gmail.com
} 
globalization in football, addressing contemporary aspects to understand the spatial distribution of the phenomenon around the world, based on the theory of the modern world-system, observing the flow of athletes in the World Cup men's soccer clubs in the years 2010-2017.

Keywords: Football; International Political Economy; Coloniality; System-Modern World.

\section{Introdução}

Em um mundo globalizado, raízes do colonialismo de alguns séculos ainda permanecem vivas na sociedade, o que justifica estudar o pós-colonialismo como perspectiva intelectual, entendendo este como a continuidade do colonialismo nos dias de hoje e nas diversas dimensões da vida social: no ponto de vista político, mas também do ponto de vista econômico, cultural e, consequentemente, do ponto de vista epistemológico, de forma intrínseca, chamada de colonialismo interno (González Casanova, 2007: 7). A partir disso, também surgem os estudos decoloniais, que buscam acabar com as formas coloniais de pensamento, principalmente na versão eurocentrista. Em suma, a perspectiva pós-colonialista, visa quebrar a epistemologia do conhecimento criada e reproduzida ao longo dos séculos (QUIJANO, 2005, p. 119).

A marca do mundo moderno é a imaginação de seus benefícios e sua refutação pelos oprimidos. A exploração e a negativa em aceitar a exploração como inevitáveis, ou justas, constitui a perene antinomia da era moderna, unidas em uma dialética, que está longe de alcançar sua culminância no século XX (WALLERSTEIN, 1974). A Perspectiva ou Análise dos Sistemas-Mundo, analisa a formação do capitalismo nos últimos cinco séculos como um sistema de alcance global e que tem suas expressões nas esferas econômica, política, social e cultural. Segundo Wallerstein (2001, p. 19), ao longo da formação desse sistema, houve mudanças nos centros hegemônicos do capitalismo, mas preservando posições centrais e periféricas. Diante disso, o sistema sempre foi uma economia-mundo baseada em trocas desiguais.

Para compreender esse mecanismo, observa-se a própria estrutura da economia-mundo, na divisão entre o espaço da economia (uma divisão social mundial do trabalho em nome da acumulação incessante de capital) e o espaço da política (organizado em torno de Estados, cada qual com responsabilidade autônoma por decisões políticas) (WALLERSTEIN, 2001, p. 29). Em busca incessante por mão-de-obra mais barata e maiores lucros, o sistema-mundo

CSOnline - Revista Eletrônica de Ciências Sociais, Juiz de Fora, n. 31 (2020) 
moderno avançou pelo mundo afora e alcançou praticamente todas as esferas da vida social. O futebol não ficou de fora: se tornou um espaço de acumulação de capital e uma atividade global.

Nessa perspectiva, a pesquisa tem o intuito de identificar como ocorre a concentração do capital, analisando as dinâmicas do sistema-mundo e a transformação do jogador em mercadoria, principalmente o fluxo de transferência de jogadores dos países periféricos aos países do centro global, seguindo a lógica colonial. Assim, o estudo visa contribuir para o entendimento da globalização no futebol, abordando aspectos contemporâneos para entender a espacialização do fenômeno ao redor do mundo, baseado na teoria do sistema-mundo moderno, observando o fluxo de atletas nas Copas do Mundo de Clubes de futebol masculino entre os anos de 2010-2017.

\section{Aspectos Gerais dos Estudos Pós-Coloniais e Decoloniais}

Como epistemologia, ética e política, o campo da pós-colonialismo aborda a política do conhecimento através dos fatos que constituem a identidade pós-colonial após a descolonização de um povo. Alguns fatores derivam de uma lógica colonial, mas principalmente a geração de conhecimento cultural do colonizador sobre os povos colonizados, e o modo de aplicação desse conhecimento cultural para subjugar um povo não-europeu em uma colônia de determinado país europeu.

Nesse sentido, é importante o colonialismo interno de Pablo González Casanova (2007, p. 2), o qual afirma que o "póscolonialismo é um conjunto de teorias que analisam os efeitos políticos, filosóficos, artísticos e literários deixados pelo colonialismo nos países colonizados. A teoria pós-colonial tornou-se conhecida nos anos 1970, a partir do livro "Orientalismo" de Edward Said, tido como a obra fundadora, descrevendo a relação social com o qual a Europa Ocidental intelectualmente dividiu 0 mundo em "Ocidente" e "Oriente". O autor desenvolveu as denotações e conotações do termo "orientalismo", principalmente como sendo a figura do "Outro" (CASTRO-GÓMEZ, 2005, p. 19-21). Mas ainda há outros autores que podem ser considerados pioneiros, tais como Frantz Fanon (1965), quem, em "Os condenados da terra", analisa clinicamente a natureza do colonialismo como essencialmente destrutivo, pois seus efeitos sociais - a imposição de uma identidade 
colonial subjugada - são prejudiciais para a saúde mental dos povos de cor que foram subjugados em colônias. "

Ao estabelecer a definição pós-colonial do termo subalterno, a filósofa e teórica Gayatri Spivak, autora da famosa obra "Pode o subalterno falar?", argumenta que povos subalternos nunca podem expressar suas formas de conhecimento (pensamento, raciocínio, linguagem), devendo, em vez disso, estar em conformidade com as formas ocidentais de conhecimento do mundo. Ainda, em "Provincializing Europe", Dipesh Chakrabarty traçou a história subalterna da luta pela independência indiana, e rebatendo o pensamento eurocentrista, propôs que a Europa Ocidental simplesmente fosse considerada culturalmente igual às outras culturas do mundo (CASTRO-GÓMEZ, 2005, p. 20-22).

Já decolonialidade não é apenas o processo de descolonização de um povo. Decolonialidade é termo usado principalmente por um movimento latino-americano emergente que tem como foco entender a modernidade no contexto de uma forma de teoria crítica aplicada a estudos étnicos. Ele foi descrito por Walter Mignolo (2005) como sendo opções analíticas e práticas que confrontam e desvinculam a matriz colonial de poder. Pode ser contrastado com a colonialidade que é "a lógica subjacente da fundação e desdobramento da civilização ocidental desde a Renascença até hoje", referida como a matriz colonial de poder ou de colonialidade do poder. Embora a colonização formal e explícita terminou com a descolonização da maioria dos países do continente americano durante $O$ século $X I X$, e com a descolonização de grande parte do sul global no final do século XX, surgiram novas formas de colonização, através da sistemática neoliberal, imperialista e globalizada, a qual perpetuou as desigualdades, principalmente sob o ponto de vista econômico.

\section{O Sistema-Mundo Moderno}

A economia-mundo é o sistema social (histórico) que surgindo na Europa no século XVI se expandiu por todo o globo terrestre. Seus componentes são o subsistema interestatal formado pelos Estados nacionais e o subsistema econômico, constituído pelas cadeias mercantis mundiais que perpassam os territórios daqueles Estados. No século XVII, com o tratado de Westphalia, constitui-se formalmente o sistema interestatal. Os Estados nacionais são, portanto, unidades políticas, formalmente autônomas e soberanas, 
nos quais, o conjunto de instituições (executivo, judiciário, parlamento) que formam o aparelho de poder. Mas cada Estado atua ou exerce sua soberania como parte do subsistema interestatal. Esse grupo de Estados compõe o centro da economiamundo, daí para baixo localizam-se os Estados com menor quota da riqueza e do poder mundiais: Estados semiperiféricos e periféricos.

No entanto, o sistema é dinâmico, em parte como resultado das revoluções em tecnologia de transporte, e os Estados individuais podem ganhar ou perder o status de núcleo (semiperiferia, periferia) ao longo do tempo. Como exemplo, se constatou que por um determinado tempo, alguns países foram hegemônicos durante os últimos séculos, mas como o sistema-mundo se estendeu geograficamente, intensificando sua atividade economicamente, esse status passou da Holanda para 0 Reino Unido e, mais recentemente, para os Estados Unidos.

Immanuel Wallerstein desenvolveu a análise de sistemas-mundo, começando na década de 1970. Para ele, (WALLERSTEIN, 2005, p. 27), a ascensão do capitalismo foi resultado da longa crise do feudalismo, em que a Europa utilizou seu controle sobre a maior parte do mundo, conquistando vantagens econômicas, presidindo o desenvolvimento e propagando a industrialização e o capitalismo que, de forma indireta, resultou em um desenvolvimento desigual.

Como movimento epistemológico, a Análise dos Sistemas-Mundo é, sobretudo, uma perspectiva analítica que visa transcender as estruturas do conhecimento herdado do século XIX. Sua visão é a de que se deve inventar uma nova linguagem, transcendendo as ilusões sociais, econômicas e políticas impostas pelos colonizadores através da alienação de mundos biofísicos. Numa análise desse sistema mundo, Restrepo e Rojas (2010, p. 72) dizem que:

Como resultado de la consolidación del sistema-mundo moderno, Europa vivió grandes transformaciones. Tal vez la de mayor incidencia tiene que ver con la legitimación de un sistema altamente desigual, tanto al interior de las sociedades europeas, como en las colonias establecidas al otro lado del Atlántico, en la naciente América. El lugar que ganó Europa en el contexto del sistema naciente la llevó a ser el centro del poder en el contexto mundial durante los siguientes siglos.

O subsistema econômico formou-se em estreita relação com o subsistema interestatal, que é composto pela rede de cadeias 
mercantis mundiais. Uma cadeia mercantil é conjunto de atividades necessárias para que uma mercadoria seja produzida e consumida. Abarca, portanto, desde a produção da matéria-prima, equipamentos, até o consumo. A extensão espacial da economiamundo é dada pela extensão das cadeias mercantis.

Os diversos nódulos que compõem uma cadeia mercantil apresentam diferentes rentabilidades, as quais são inversamente proporcionais à competição verificada neste nódulo. Ao se concentrarem em diferentes regiões do globo, os nódulos de alta, média e baixa rentabilidade acabam segmentando a economiamundo em três regiões econômicas: centro, semiperiferia e periferia, as quais coincidem em grande parte com certo grupo de Estados: os centrais, os semiperiféricos e os periféricos. Por abrigarem a maior parte das atividades de alta rentabilidade, os países centrais se apropriam da maior ou de grande parte da riqueza produzida ao longo da cadeia.

O sistema-mundo moderno é heterogêneo em termos culturais, políticos e económicos, possuindo grandes diferenças de desenvolvimento civilizacional, acumulação de capital e poder político. Immanuel Wallerstein (2005, p. 47) atribui estas diferenças à própria natureza do sistema-mundo. Outro autor importante nos estudos do sistema-mundo é Giovanni Arrighi, com sua trilogia de livros sobre o tema: "O Longo Século XX: dinheiro, poder e as origens de nosso tempo", "Caos e governabilidade no moderno sistema mundial" e "Adam Smith em Pequim: Origens e Fundamentos do Século XXI". Arrighi (1996, p. 27) considera que a hegemonia está ligada à competência de um Estado para exercer funções de liderança e governo.

Arienti e Filomeno (2007, p. 105) versam que "o capitalismo expandiu-se territorialmente para integrar novas áreas sob seu domínio. Essa expansão realizou-se por meio de capitais respaldados pelos Estados nacionais. Paralelamente à formação da economia-mundo capitalista, havia também a manutenção e o acirramento da rivalidade entre os Estados nacionais, não mais movidos apenas pela pilhagem ou pela conquista territorial para arrecadação de tributos, como era esperado na expansão de um império, mas para apoiar os seus capitais, organizar uma divisão do trabalho mais ampla, garantir condições de monopólio para seus capitais e, com isso, gerar maiores rendas e arrecadar tributos".

O sistema internacional oscila entre momentos de caos e governabilidade, sendo esta derivada de um poder hegemônico 
que exerce papel central na economia-mundo e o caos decorrente da crise hegemônica, ou seja, uma escalada da competição e dos conflitos que ultrapassa a capacidade reguladora das estruturas existentes (ARRIGHI; SILVER, 2001, p. 42). No que tange à análise histórica, iniciou-se com o domínio holandês no século XVII, após ele houve domínio inglês no século XIX e, por fim, o norte-americano no século XX. Em contrapartida, percebese a ascensão do Leste da Ásia como "o centro mais dinâmico dos processos de acumulação de capital" em que a China exerce o papel central. Em "Adam Smith em Pequim: Origens e fundamentos do Século XXI", Arrighi (2008) busca uma explicação teórica e histórica para o ressurgimento econômico e político da Ásia Oriental, que tem a China como centro dinâmico.

Contudo, dentro dessa sistemática, o centro ainda é a área de grande desenvolvimento tecnológico, sendo a periferia a área que fornece matérias-primas, produtos agrícolas e força de trabalho barata. Em razão disso, a troca econômica entre periferia e centro é desigual, já que a periferia tem de vender barato os seus produtos enquanto compra caro os produtos do centro.

\section{Modernidade, Colonialidade e Futebol}

Nesse sentido, o futebol mostra essa lógica através do seu mercado, o qual gira verdadeiras fortunas nos países de centro (e, muitas vezes, também nos de periferia). Grandes atletas de países periféricas, ou também chamado sul global, acabam indo jogar na Europa ou em países do norte global. Buscou-se entender os paradigmas sociais, culturais, políticos e econômicos no contexto da produção de bens simbólicos enquanto mercadorias, percebendo a estrutura da economia política no futebol, de forma que se entenda como as relações ocorrem na prática.

Foi feita a coleta de dados dos atletas que disputaram a Copa do Mundo de Clubes da FIFA, no futebol masculino, dos anos de 2010 até 2017, onde havia representantes de todos os continentes, onde o campeão de cada continente e do país sede disputavam o evento. Foi analisado a origem dos atletas de cada equipe, buscando entender a lógica do mercado do futebol masculino, como se dá o fluxo de atletas entre os continentes. 
Copa do Mundo de Clubes da FIFA (2010-2017): reprodução da colonialidade

\begin{tabular}{|c|c|c|c|c|c|c|c|c|}
\hline \multicolumn{9}{|c|}{ MUNDIAL DE CLUBES 2010} \\
\hline Equipes & Atletas & Nacionais & \multicolumn{6}{|c|}{ Estrangeiros } \\
\hline & & & $\begin{array}{c}\text { América } \\
\text { Latina }\end{array}$ & África & Ásia & Oceania & Europa & $\begin{array}{l}\text { América } \\
\text { do Norte }\end{array}$ \\
\hline Inter (BRA) & 23 & 20 & 3 & & & & & \\
\hline $\begin{array}{l}\text { Hekari } \\
\text { (PNG) }\end{array}$ & 23 & 11 & & & & 12 & & \\
\hline $\begin{array}{c}\text { Al Wahda } \\
\text { (EAU) }\end{array}$ & 23 & 19 & 3 & 1 & & & & \\
\hline Inter (ITA) & 23 & 5 & 8 & 4 & & & 6 & \\
\hline $\begin{array}{c}\text { Mazembe } \\
(\mathrm{CON})\end{array}$ & 23 & 19 & & 4 & & & & \\
\hline $\begin{array}{c}\text { Pachuca } \\
(M E X)\end{array}$ & 23 & 15 & 6 & & & & & 2 \\
\hline $\begin{array}{c}\text { Seongnam } \\
\text { (COR) }\end{array}$ & 23 & 20 & 1 & & & 1 & 1 & \\
\hline
\end{tabular}

\begin{tabular}{|c|c|c|c|c|c|c|c|c|}
\hline \multicolumn{9}{|c|}{ MUNDIAL DE CLUBES 2011} \\
\hline Equipes & Atletas & Nacionais & & & & rangeiros & & \\
\hline & & & $\begin{array}{l}\text { América } \\
\text { Latina }\end{array}$ & África & Ásia & Oceania & Europa & $\begin{array}{l}\text { América } \\
\text { do Norte }\end{array}$ \\
\hline $\begin{array}{c}\text { Al-Sadd } \\
\text { (CAT) }\end{array}$ & 23 & 18 & 1 & 3 & 1 & & & \\
\hline $\begin{array}{l}\text { Auckland } \\
\text { City (NZL) }\end{array}$ & 23 & 15 & 2 & & & & 6 & \\
\hline $\begin{array}{c}\text { Barcelon } \\
\text { a (ESP) }\end{array}$ & 23 & 14 & 7 & 1 & & & 1 & \\
\hline $\begin{array}{c}\text { Espéranc } \\
\text { e (TUN) }\end{array}$ & 23 & 19 & & 4 & & & & \\
\hline $\begin{array}{c}\text { Kashiwa } \\
\text { (JAP) }\end{array}$ & 23 & 19 & 2 & & 2 & & & \\
\hline $\begin{array}{l}\text { Monterre } \\
\text { y (MEX) }\end{array}$ & 23 & 18 & 5 & & & & & \\
\hline $\begin{array}{c}\text { Santos } \\
\text { (BRA) }\end{array}$ & 23 & 22 & 1 & & & & & \\
\hline
\end{tabular}

\begin{tabular}{|c|c|c|c|c|c|c|c|c|}
\hline \multicolumn{7}{|c|}{ MUNDIAL DE CLUBES 2012 } \\
\hline Equipes & Atletas & Nacionais & \multicolumn{5}{|c|}{ Estrangeiros } \\
\hline & & $\begin{array}{c}\text { América } \\
\text { Latina }\end{array}$ & África & Ásia & Oceania & Europa & $\begin{array}{c}\text { América } \\
\text { do Norte }\end{array}$ \\
\hline $\begin{array}{c}\text { Al-Ahly } \\
\text { (EGT) }\end{array}$ & 23 & 22 & & 1 & & & & \\
\hline $\begin{array}{c}\text { Auckland } \\
\text { City (NZL) }\end{array}$ & 22 & 12 & 2 & & 1 & 1 & 6 & \\
\hline $\begin{array}{c}\text { Chelsea } \\
\text { (ING) }\end{array}$ & 23 & 8 & 4 & 2 & & & 9 & \\
\hline $\begin{array}{c}\text { Corinthia } \\
\text { ns (BRA) }\end{array}$ & 23 & 21 & 2 & & & & & \\
\hline $\begin{array}{c}\text { Monterre } \\
\text { y (MEX) }\end{array}$ & 23 & 18 & 5 & & & & & \\
\hline $\begin{array}{c}\text { Sanfrecc } \\
\text { (JAP) }\end{array}$ & 23 & 21 & & & 1 & & 1 & \\
\hline $\begin{array}{c}\text { Ulsan } \\
\text { Hyundai } \\
\text { (COR) }\end{array}$ & 23 & 20 & 3 & & & & & \\
\hline
\end{tabular}


Copa do Mundo de Clubes da FIFA (2010-2017): reprodução da colonialidade

\begin{tabular}{|c|c|c|c|c|c|c|c|c|}
\hline \multicolumn{9}{|c|}{ MUNDIAL DE CLUBES 2013} \\
\hline Equipes & Atletas & Nacionais & & & & trangeiros & & \\
\hline & & & $\begin{array}{l}\text { América } \\
\text { Latina }\end{array}$ & África & Ásia & Oceania & Europa & $\begin{array}{l}\text { América } \\
\text { do Norte }\end{array}$ \\
\hline $\begin{array}{l}\text { Al-Ahly } \\
\text { (EGT) }\end{array}$ & 22 & 22 & & 1 & & & & \\
\hline $\begin{array}{c}\text { Atlético } \\
\text { Mineiro } \\
\text { (BRA) }\end{array}$ & 23 & 23 & & & & & & \\
\hline $\begin{array}{l}\text { Auckland } \\
\text { City (NZL) }\end{array}$ & 23 & 10 & 1 & & 1 & 2 & 9 & \\
\hline $\begin{array}{c}\text { Bayern } \\
\text { München } \\
\text { (ALE) }\end{array}$ & 23 & 11 & 3 & & & & 8 & 1 \\
\hline $\begin{array}{c}\text { Guangzhou } \\
(\mathrm{CHI})\end{array}$ & 23 & 18 & 3 & & 1 & & & \\
\hline $\begin{array}{c}\text { Monterrey } \\
(M E X)\end{array}$ & 23 & 16 & 7 & & & & & \\
\hline $\begin{array}{c}\text { Raja } \\
\text { Casablanca } \\
\text { (MAR) }\end{array}$ & 23 & 19 & & 4 & & & & \\
\hline
\end{tabular}

\begin{tabular}{|c|c|c|c|c|c|c|c|c|}
\hline \multicolumn{9}{|c|}{ MUNDIAL DE CLUBES 2014} \\
\hline Equipes & Atletas & Nacionais & & & & trangeiros & & \\
\hline & & & $\begin{array}{l}\text { América } \\
\text { Latina }\end{array}$ & África & Ásia & Oceania & Europa & $\begin{array}{l}\text { América } \\
\text { do Norte }\end{array}$ \\
\hline $\begin{array}{l}\text { Auckland } \\
\text { City (NZL) }\end{array}$ & 23 & 9 & 1 & 1 & 2 & 1 & 9 & \\
\hline $\begin{array}{c}\text { Cruz Azul } \\
\text { (MEX) }\end{array}$ & 23 & 19 & 4 & & & & & \\
\hline $\begin{array}{c}\text { Sétifienne } \\
\text { (ARL) }\end{array}$ & 23 & 21 & & 2 & & & & \\
\hline $\begin{array}{c}\text { Tétouan } \\
\text { (MAR) }\end{array}$ & 23 & 20 & & 1 & & & 2 & \\
\hline $\begin{array}{l}\text { Real } \\
\text { Madrid } \\
\text { (ESP) }\end{array}$ & 22 & 10 & 4 & & & & 8 & \\
\hline $\begin{array}{l}\text { San } \\
\text { Lorenzo } \\
\text { (ARG) }\end{array}$ & 23 & 22 & 1 & & & & & \\
\hline $\begin{array}{c}\text { Wanderers } \\
\text { (AUS) }\end{array}$ & 23 & 18 & 1 & 1 & & & 3 & \\
\hline
\end{tabular}


Copa do Mundo de Clubes da FIFA (2010-2017): reprodução da colonialidade

\begin{tabular}{|c|c|c|c|c|c|c|c|c|}
\hline \multicolumn{9}{|c|}{ MUNDIAL DE CLUBES 2015} \\
\hline Equipes & Atletas & Nacionais & & & & trangeiros & & \\
\hline & & & $\begin{array}{c}\text { América } \\
\text { Latina }\end{array}$ & África & Ásia & Oceania & Europa & $\begin{array}{l}\text { América } \\
\text { do Norte }\end{array}$ \\
\hline $\begin{array}{l}\text { Auckland } \\
\text { City (NZL) }\end{array}$ & 23 & 11 & 1 & & 2 & 1 & 8 & \\
\hline $\begin{array}{l}\text { Barcelona } \\
\text { (ESP) }\end{array}$ & 23 & 11 & 8 & & & & 4 & \\
\hline $\begin{array}{c}\text { River Plate } \\
\text { (ARG) }\end{array}$ & 23 & 18 & 5 & & & & & \\
\hline $\begin{array}{c}\text { América } \\
\text { (MEX) }\end{array}$ & 23 & 14 & 9 & & & & & \\
\hline $\begin{array}{c}\text { Mazembe } \\
(\mathrm{CON})\end{array}$ & 23 & 6 & & 17 & & & & \\
\hline $\begin{array}{c}\text { Guangzhou } \\
(\mathrm{CHI})\end{array}$ & 23 & 17 & 5 & & 1 & & & \\
\hline $\begin{array}{c}\text { Sanfrecce } \\
\text { (JAP) }\end{array}$ & 23 & 21 & 1 & & & & 1 & \\
\hline
\end{tabular}

\begin{tabular}{|c|c|c|c|c|c|c|c|c|}
\hline \multicolumn{9}{|c|}{ MUNDIAL DE CLUBES 2016} \\
\hline Equipes & Atletas & Nacionais & & & & rangeiros & & \\
\hline & & & $\begin{array}{l}\text { América } \\
\text { Latina }\end{array}$ & África & Ásia & Oceania & Europa & $\begin{array}{l}\text { América } \\
\text { do Norte }\end{array}$ \\
\hline $\begin{array}{l}\text { Auckland } \\
\text { City (NZL) }\end{array}$ & 23 & 10 & 1 & & 2 & 1 & 9 & \\
\hline $\begin{array}{l}\text { Real } \\
\text { Madrid } \\
\text { (ESP) }\end{array}$ & 23 & 10 & 5 & & & & 8 & \\
\hline $\begin{array}{l}\text { Atlético } \\
\text { Nacional } \\
\text { (COL) }\end{array}$ & 23 & 19 & 4 & & & & & \\
\hline $\begin{array}{l}\text { América } \\
\text { (MEX) }\end{array}$ & 23 & 11 & 11 & & & & & 1 \\
\hline $\begin{array}{l}\text { Mamelodi } \\
\text { Sundowns } \\
\text { (AFS) }\end{array}$ & 23 & 16 & 2 & 5 & & & & \\
\hline $\begin{array}{c}\text { Jeonbuk } \\
\text { (COR) }\end{array}$ & 23 & 21 & 2 & & & & & \\
\hline $\begin{array}{c}\text { Kashima } \\
\text { Antlers } \\
\text { (JAP) }\end{array}$ & 23 & 20 & 2 & & 1 & & & \\
\hline
\end{tabular}




\begin{tabular}{|c|c|c|c|c|c|c|c|c|}
\hline \multicolumn{9}{|c|}{ MUNDIAL DE CLUBES 2017} \\
\hline Equipes & Atletas & Nacionais & \multicolumn{6}{|c|}{$\begin{array}{ll}\text { Estrangeiros } \\
\end{array}$} \\
\hline & & & $\begin{array}{c}\text { América } \\
\text { Latina }\end{array}$ & África & Ásia & Oceania & Europa & $\begin{array}{l}\text { América } \\
\text { do Norte }\end{array}$ \\
\hline $\begin{array}{l}\text { Auckland } \\
\text { City (NZL) }\end{array}$ & 23 & 11 & 1 & & 2 & 1 & 8 & \\
\hline $\begin{array}{l}\text { Real Madrid } \\
\text { (ESP) }\end{array}$ & 23 & 11 & 3 & 1 & & & 8 & \\
\hline $\begin{array}{c}\text { Grêmio } \\
\text { (BRA) }\end{array}$ & 23 & 21 & 2 & & & & & \\
\hline $\begin{array}{c}\text { Pachuca } \\
\text { (MEX) }\end{array}$ & 23 & 15 & 6 & & 1 & & & 1 \\
\hline $\begin{array}{c}\text { Wydad } \\
\text { Casablanca } \\
\text { (MAR) }\end{array}$ & 23 & 20 & & 3 & & & & \\
\hline $\begin{array}{c}\text { Al Jazira } \\
\text { (EAU) }\end{array}$ & 23 & 19 & 1 & 2 & 1 & & & \\
\hline $\begin{array}{c}\text { Urawa Reds } \\
\text { (JAP) }\end{array}$ & 23 & 20 & 2 & & & & 1 & \\
\hline
\end{tabular}

Elaboração própria. Fonte: Fifa, 2020.

A primeira análise feita é sobre o número de atletas do sul-global presentes em equipes do mundo inteiro. Das 56 equipes analisadas apenas uma do chamado norte-global não possuía atletas latinoamericanos ou africanos, o que já demonstra como há um fluxo grande de atletas do sul global para esses continentes.

Outra análise é o número irrisório de jogadores do norte-global que jogam por equipes do sul-global, de 1.288 apenas 6 atletas (2 europeus e 4 norte-americanos) representando 4 equipes. Em contrapartida, observando apenas as equipes europeias, são 50 atletas latino-americanos e africanos, isso sem contar as variáveis como, por exemplo, o limite que a UEFA (confederação europeia de futebol) permite para jogadores estrangeiros, o que acarretar em um número muito maior. Mosco (apud SANTOS, 2014, p. 570) afirma que "o uso do poder político e econômico contém um valor consideravelmente explicativo para compreender 0 êxito da mercantilização. O processo reduz os recursos, o tempo e o espaço disponíveis para as alternativas, pelo que a mercantilização se percebe não como um processo de poder senão como a ordem natural, o sentido comum, a realidade da vida social. $O$ poder institucional, que fomenta uma lógica e elimina as alternativas, é central para a construção da hegemonia. Porém existe também a questão do vínculo entre o valor de uso e o valor de troca. Para o valor de troca, amplia não apenas ao minar os valores de uso e de não mercadoria, senão também ao usar estes valores para realizar 
seu próprio atrativo e, no processo, ao transformar os valores de uso em valores de troca. "

Ainda, se contar países do norte-global, como Japão, Nova Zelândia, Austrália, Coréia do Sul, Catar e Emirados Árabes, aumenta em mais 36 o número de atletas latino-americanos e africanos. Outro dado interessante é o crescimento de jogadores do sul-global no mercado chinês, que vem expandindo e é um ator de extrema relevância para ser analisado nas teorias do SistemaMundo.

\section{Considerações Finais}

O caráter de difusão do esporte, principalmente através do transnacionalismo que o futebol traz consigo, em especial com a globalização, evidencia uma mudança de paradigmas no atual sistema-mundo, em que a cada ano se passa a ter a transferência de bons jogadores para determinados países da periferia para o centro. $O$ futebol mudou e se desenvolveu durante os anos diante das transformações vivenciadas no modo de produção capitalista, com vários fatores em volta da indústria do espetáculo.

A partir dessa lógica, com uma ideia crítica à economia política internacional, a pesquisa buscou analisar o futebol como um instrumento que evidencia essas dinâmicas no sistema-mundo moderno. Nesse contexto, em meio a desigualdade no desenvolvimento do futebol em relação às seleções nacionais e entre clubes, onde há a apropriação por entidades paraestatais, criando regras para competições "igualitárias", como defendia o capitalismo liberal. Bolaño (apud SANTOS, 2014, p. 565) aponta que há um processo de edificação de uma ordem esportiva que, partindo do mundo da vida, sobrepõe-se a ele e o coloniza.

Apesar disso, existem contradições do capital no que tange às atividades esportivas, principalmente se tratando de futebol. $O$ esporte gera produtos a serem repassados para o restante do mundo, inclusive em países periféricos, a ponto de os europeus, verem os países sul-americanos dividirem as forças nos principais campeonatos do mundo, mesmo sob condições financeiras piores, havendo uma quebra da lógica centro-periferia em alguma parte do tempo.

Juntamente com a economia política na transferência de atletas, se pode citar o comércio de materiais esportivos, propagandas em uniformes, direitos de transmissão, dentre outras formas de 
acumulação de capital. Todos esses objetos são passíveis de investigação acadêmica, em que se trarão mais evidências através de pesquisas científicas que irão corroborar com os dados coletados até aqui.

Tudo isso origina novas formas de mercantilização a partir de instrumentos de manutenção do capital. Ainda assim, por mais que o peso político-econômico exista, o futebol é um campo de conflitos simbólicos e de expressão transcultural, sendo um importante objeto de estudos para as Ciências Humanas.

\section{Referências Bibliográficas}

ARIENTI, Wagner Leal; Filomeno, Felipe Amin. (2007). Economia política do moderno sistema mundial: as contribuições de Wallerstein, Braudel e Arrighi. Ensaios FEE. Porto Alegre, v. 28, n. 1, p. 99-126.

ARRIGHI, Giovanni. (2008). Adam Smith em Pequim: origens e fundamentos do século XXI. Boitempo Editorial, São Paulo.

ARRIGHI, Giovanni. (1996). O Longo Século XX: dinheiro, poder e as origens de nosso tempo. UNESP, Rio de Janeiro.

ARRIGHI, Giovanni. Silver, Beverly J. (2001). Caos e governabilidade no moderno sistema mundial. Rio de Janeiro: Contraponto; Editora UFRJ.

CASTRO-GÓMEZ, Santiago. (2005). La Poscolonialidad explicada a los niños. Bogotá: Universidad del Cauca y Instituto Pensar.

FANON, Frantz. (1968). Os condenados da Terra. Trad. José Lourênio de Melo. Rio de Janeiro: Civilização Brasileira.

FIFA. (2020). Official Documents. Zurique. Disponível em:

<http://www.fifa.com/about-fifa/official-documents/development/technicalstudy-group-reports/index.html> Acesso em: 07 jan. 2020.

GONZÁLEZ CASANOVA, Pablo. (2007). Colonialismo interno (uma redefinição). En publicación: A teoria marxista hoje - Problemas e perspectivas. Boron, Atilio A.; Amadeo, Javier; Gonzalez, Sabrina.

MIGNOLO, Walter. (2005). La idea de América Latina: la herida colonial y la opción decolonial. Barcelona, Gedisa Editorial.

QUIJANO, Aníbal. (2005). Colonialidade do poder, eurocentrismo e América Latina. In: Lander, Edgardo (org). A colonialidade do saber: eurocentrismo e ciências sociais, perspectivas latino-americanas. Buenos Aires: Clacso.

RESTREPO, Eduardo; Rojas, Axel. (2010). Inflexión decolonial. Popayán, Colombia, Universidad del Cauca, Instituto Pensar, Universidad Javeriana, 234 pp.

SANTOS, Anderson David Gomes dos. (2014). Os três pontos de entrada da economia política no futebol. Revista Brasileira de Ciências do Esporte, Porto Alegre, v. 36, n. 2. p. 561-575. 
Copa do Mundo de Clubes da FIFA (2010-2017): reprodução da colonialidade

WALLERSTEIN, Immanuel. (1974). The modern world-system. Capitalist agriculture and the origins of the European world-economy in the 16th. century. New York, Academic Press, v. 1.

WALLERSTEIN, Immanuel. (2001). Capitalismo histórico e civilização capitalista. Rio de Janeiro: Editora Contraponto, tradução de Renato Aguiar, revisão da tradução de César Benjamin. 144 p.

WALLERSTEIN, Immanuel. (2005). Análisis de sistemas-mundo: una introducción. México: Siglo XXI Editores. 